\title{
Combined Effect of Rainfall Seepage and Seismic Shaking on Slope Stability by Using a Three-Dimensional Stability Analysis
}

\author{
Chien-Yuan Chen and Wei-Cheng Wu
}

\begin{abstract}
Taiwan is located in the Pacific Rim seismic zone and has a subtropical climate and mountainous areas. As a limited amount of area in Taiwan can be categorized as plains, the mountainous areas are used for development requirements. Overdevelopment on weak slope lands causes them to collapse and further exposes the lands to natural disasters such as earthquakes and torrential rains. Thus, appropriate slope stability analysis methods and engineering design measures should be proposed for slope lands. The purpose of this study was to discuss the combined effect of seismic shaking and soil seepage due to rainfall on slope lands by analyzing their combined effect on the factor of safety (FS) and failure mode of a slope land. A slope stability analysis was conducted using finite difference analysis, performed with FLAC3D. The soil strength reduction method was adopted to identify the FS of slopes in a static state by using FLAC3D. The formation of plastic sliding zones as the ratio of soil strength reduction was defined as FS in the seismic analysis. This study employed earthquake time history data of the Chi-Chi earthquake recorded at the Shihgang Dam station in the central region of Taiwan. The combined effect of seismic shaking and soil seepage due to rainfall was analyzed to determine its influence on the FS of the slope. The proposed method, which analyzes the combined effect of seismic shaking and rainfall seepage on the FS, obtains superior results to the conventional method, which analyzes the effects of seismic shaking and rainfall seepage separately.
\end{abstract}

Index Terms-Slope stability, seepage, finite difference, seismic analysis.

\section{INTRODUCTION}

Earthquake and rainfall-induced seepage are the main factors that cause slopes to become unstable. Rainfall seepage increases soil pore water pressure and soil saturation, thus reducing the effective shear strength and increasing the weight of soil. In state-of-the-art analyses, earthquake- and rainfall-induced slope stability is evaluated separately. The effect of soil saturation due to excessive rainfall and preceding a landslide was examined [1]. Numerous researchers have conducted post-earthquake rainfall-triggered slope stability analyses [2], [3]. The analysis results revealed that a slope can be stable after the occurrence of an earthquake or after a rainfall event, but the stability of a slope is adversely affected when an earthquake occurs after a rainfall event. During the 2006 Southern Leyte

Manuscript received June 12, 2018; revised October 12, 2018.

Chien-Yuan Chen and Wei-Cheng Wu are with the Department of Civil and Water Resources Engineering, National Chiayi University, Chiayi City 60004, Taiwan (e-mail: chienyuc@mail.ncyu.edu.tw, s1040438@alumni.ncyu.edu.tw). mudslide in the Philippines, the rainfall was highest (131 to $171 \mathrm{~mm}$ ) during February 10-12, 2006, around the same time as two earthquakes were recorded [4]. The relevance of the heavy rainfall and almost synchronous seismic event was investigated in one study, but the landslide was concluded to be due to progressive failure of the rock slope and tectonic weakening, with the landslide aggravated by the presence of rice paddy fields in the bottom of the valley [5]. By contrast, [6] argued that the 2006 Southern Leyte mudslide was possibly triggered due to the combined effect of the small-magnitude earthquake and the heavy rain.

The soil shear strength reduction (SSR) method is a numerical analysis method commonly used for evaluating the factor of safety (FS) of a slope when the slope undergoes external disturbance. The SSR method reduces the soil shear strength parameters - cohesion strength (c) and friction angle $(\varphi)$ - at the same ratio until the slope becomes unstable. The point at which the slope model becomes unstable is defined as the FS of the slope [7]. In this method, the soil shear strength is reduced by using the following equations:

$$
\begin{aligned}
& c_{F}=\left(\mathrm{c} / F_{\text {trial }}\right) \\
& \varphi_{F}=\tan ^{-1}\left(\tan \varphi / F_{\text {trial }}\right)
\end{aligned}
$$

where $c_{F}$ and $\varphi_{F}$ are the reduced soil shear strength parameters at the trial ratio $F_{\text {trial }}$.

The criteria for determining the FS of a slope using the SSR method are as follows:

(a) Nonconvergent numerical calculation [8]

A slope enters the failure stage because the out-of-balance forces at a node are unable to converge during the numerical calculation. The FS of a slope can be obtained by analyzing the Mohr-Coulomb failure criteria and overall equilibrium of the system during the numerical analysis [9]-[10].

(b) Displacement abruptly increased at specific points [11]

Slope displacement increases abruptly at the critical stage, thus causing slope failure. In this case, a slope's FS is equivalent to the SSR factor [12]-[13].

(c) Plastic zone deformation [7]

Plastic deformation occurs when the soil shear strength is reduced under gravity. Slope failure occurs due to failure at the plastic zone, which stretches from the foot to the tip of the slope. A slope's FS corresponds to the soil SSR ratio at which the failure occurs.

(d) Combined criterion

This criterion combines both aforementioned methods. For instance, an abrupt increase in displacement at specific points 
and plastic zone deformation can be used for identifying the FS of a slope during stability analysis.

Criteria (a) and (c), nonconvergent numerical calculation and plastic zone deformation, can be affected by other factors. Thus, the unique of FS and its reasonability are doubt. Plastic deformation can be easily observed in two-dimensional (2D) profiles but experience is required to identify it in three-dimensional (3D) profiles. Slope displacement can be caused by water erosion and the displaced slope can return to the original position after seismic shaking. Thus, point selection for tracing the displacement path requires trained and experienced individuals.

The aforementioned previous studies separately conducted slope stability analysis regarding seismic shaking and rainfall seepage. However, the combined effect of seismic shaking and rainfall seepage on a slope's stability has not yet been analyzed.

\section{METHODS}

\section{A. Modeling Phases}

In this study, a slope's stability was analyzed under static conditions, rainfall seepage, and seismic shaking by using the finite difference package FLAC3D [14]. Three cases were designed for exploring the changes in a sliding surface and the FS of the slope. In Case 1, a conventional method was employed to study water seepage due to an elevated water table and the effects on the slope's FS. In Case 2, 3D seismic shaking analyses were performed to identify the changes in the FS of a slope under 3D seismic shaking. In Case 3, stability analysis was conducted to determine the combined effect of water seepage in the ground, which caused the groundwater level to increase, and 3D seismic shaking.

A slope gradient of $30^{\circ}$ was used for the slope stability analysis under static conditions, for 3D seismic excitations, and for rainfall-induced water seepage conditions (Fig. 1).

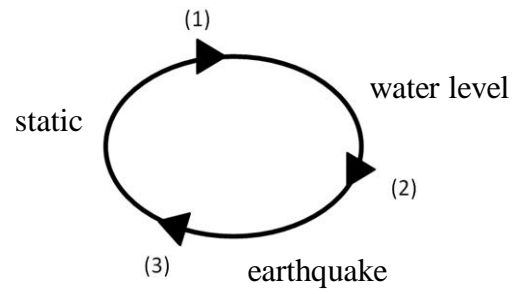

\footnotetext{
(1) water level increasing

(2) earthquake

(3) water level + earthquake
}

Fig. 1. Modeling phases of the slope stability analysis: Static, water-induced seepage, and seismic shaking conditions.

FLAC3D is numerical modeling software for explicit finite difference analysis. The external forces induce out-of-balance forces at the nodes; these forces, the node velocity, and the strain rate are calculated using the transportation equation. Node displacement is calculated by integrating the node velocity and corresponding strain rate. The stress-strain law is used to identify a new stress increment and to update the out-of-balance forces at the nodes. The iteration process continues until the out-of-balance forces at the nodes fall below a defined threshold value.

The analysis steps in FLAC3D can be simplified as follows: (1) Set finite difference grids; (2) Define a constitutive model and the material parameters; (3) Set the initial and boundary conditions.

The model reaches an initial equilibrium after undergoing all the analysis steps. A response analysis is then conducted by subjecting the model to stresses, strains, and changes in the boundary conditions.

To simply the numerical analysis in this study, soil was assumed to be a homogeneous and isotropic material and no water table was considered initially. In the initial phase, only a single soil layer on base rock is considered. The soil strength can be estimated by using the Mohr-Coulomb failure criteria. The soil shear strength parameters of the model were the bulk modulus $(\mathrm{K})$, cohesion $(\mathrm{c})$, shear dilation angle $(\psi)$, internal friction angle $(\varphi)$, and shear modulus $(\mathrm{G})$. For the base rock, $\mathrm{K}$, shear modulus $(\mathrm{G})$, and Young's modulus (E) were required. The soil parameters used in the FLA3D analysis are listed in Table I.

TABLE I: MATERIAL PARAMETERS USED IN FLAC3D SIMULATIONS

\begin{tabular}{|l|l|l|l|}
\hline Parameters & Value & Parameters & Value \\
\hline soil cohesion & $12.4 \mathrm{kPa}$ & soil unit weight & $20 \mathrm{kN} / \mathrm{m}^{3}$ \\
\hline $\begin{array}{l}\text { soil friction } \\
\text { angle }\end{array}$ & $20^{\circ}$ & soil elastic modulus & $9.6 \mathrm{MPa}$ \\
\hline $\begin{array}{l}\text { rock elastic } \\
\text { modulus }\end{array}$ & $24 \mathrm{GPa}$ & rock Poisson ratio & 0.20 \\
\hline
\end{tabular}

\section{B. Seepage Principles for Saturated and Unsaturated Soil}

Water seepage increases down-slope forces, reduces soil shear strength, and deteriorates slope stability. By using the Mohr-Column failure criteria, this study investigated the effect of rainfall water seepage on pore water pressure and slope stability.

The water seepage discharge on saturated or unsaturated soil is modeled using Darcy's law as follows [14]:

$$
q_{i}=-k_{i j} \hat{\mathrm{k}}(\mathrm{s}) \frac{\partial}{\partial x_{j}}\left(p-\rho_{w} g_{k} x_{k}\right)
$$

where $q_{i}$ represents the discharge rate of the fluid, $k_{i j}$ represents the mobility coefficient, $\widehat{k}(\mathrm{~s})$ represents the relative permeability and is a function of soil saturation (s), p represents the fluid pressure, $\rho_{w}$ represents the fluid mass density, and $g_{k}$ represents gravity acceleration in directions $k$ $=1,2,3$.

The relationships between soil saturation (s), fluid volumetric change $(\zeta)$, and fluid pressure $(p)$ can be expressed as follows:

$$
\frac{1}{M} \frac{\partial p}{\partial t}+\frac{n}{s} \frac{\partial s}{\partial t}=\frac{1}{s} \frac{\partial \zeta}{\partial t}
$$

where $M$ represents the specific modulus $\left(\mathrm{N} / \mathrm{m}^{2}\right)$, n represents the porosity, $t$ is the time, and $\zeta$ represents the change in fluid volume induced by fluid diffusion per unit.

The soil saturation is set as $100 \%(\mathrm{n}=0)$ at the grid nodes during the seepage analysis using FLAC $3 \mathrm{D}$, and the pore water pressure ( $\mathrm{p})$ is defined as follows:

$$
\frac{1}{M} \frac{\partial p}{\partial t}=\frac{1}{s} \frac{\partial \zeta}{\partial t}
$$


In the non-saturated area, the seepage analysis can be expressed as follows:

$$
\frac{n}{s} \frac{\partial s}{\partial t}=\frac{1}{s} \frac{\partial \zeta}{\partial t}
$$

The equation reveals that the unsaturated soil state changes with changes in the fluid volume. The water seepage process requires a long time to analyze numerically. To simplify the process, a constant pressure boundary was set at the slope surface, and the pore water pressure was calculated using the hydraulic gradient to model the increase in water level. The soil and base rock parameters used in the rainfall seepage analysis are listed in Table II.

TABLE II: SOIL AND BASE Rock PARAMETERS OF RAINFALl SEEPAGE ANALYSIS

\begin{tabular}{lll} 
& \multicolumn{2}{c}{ ANALYSIS } \\
\hline Parameter & Sandy clay & Base rock \\
\hline $\begin{array}{l}\text { Permeability, } \\
\mathrm{k}\left(\mathrm{m}^{2} / \mathrm{Pa}-\mathrm{sec}\right)\end{array}$ & $1.02 \times 10^{-13}$ & $1.02 \times 10^{-12}$ \\
Porosity, $\mathrm{n}$ & 0.38 & 0.22 \\
\hline
\end{tabular}

\section{Soil SSR Criteria}

A design grid with a $30^{\circ}$ slope was used to analyze the combined effect of rainfall and an earthquake on the FS of the slope. No water table was considered initially. Static, seismic, and seepage conditions were employed in slope stability analysis and the results compared. For analyzing the static conditions, a bisection method [15] was used for FS analysis in the SSR method. The method defines the upper and lower bounds of the FS of the slope and then reduces these upper and lower bounds until the difference between the two values is less than the critical value of 0.02 . The average value obtained is defined as the FS of the slope. Moreover, each calculation should agree with the following two conditions: (1) the out-of-balance forces should be smaller than the threshold value of $1 \times 10^{-5}$ and (2) the number of time steps should be more than 300000 . The slope is stable (unstable) when the out-of-balance forces at the nodes are smaller (larger) than the threshold value. The operation stops when the calculation meets the first condition, at which point the lower bound is increased to renew the calculation. The operation stops when the first condition cannot be satisfied, at which point the upper bound is reduced to renew the calculation. The FS of the slope is considered to be the average value of $\mathrm{Ks}$ once the calculation algorithm has finished.

The trial value of Ks was manually input to the large deformation-coupled calculation algorithm during the seismic analysis. The value of Ks was increased or reduced and any resultant plastic deformation was noted. The minimum Ks value that caused plastic deformation of the slope was defined as the FS of the slope.

\section{Seismic Slope Stability Analysis}

The earthquake time history data of the Chi-Chi earthquake, which were recorded at the Shihgang Dam station in the central region of Taiwan, were used for the seismic analysis in this study. The data was used for analyzing the effects of vertical acceleration on slope stability. The base of the boundary is setting as a rigid base for conducting seismic analysis. The selected earthquake time history data reveal a peak acceleration of $0.37 \mathrm{~g}$ in the North-South $(\mathrm{N}-\mathrm{S})$ direction, $0.51 \mathrm{~g}$ in the East-West $(\mathrm{E}-\mathrm{W})$ direction, and $0.53 \mathrm{~g}$ in the vertical direction. The highest vertical acceleration was selected for analyzing the maximum effects of vertical acceleration in the slope stability analysis. Seismic 3D shaking was evaluated after the baseline correction was applied at the bases of the grids (Fig. 2).
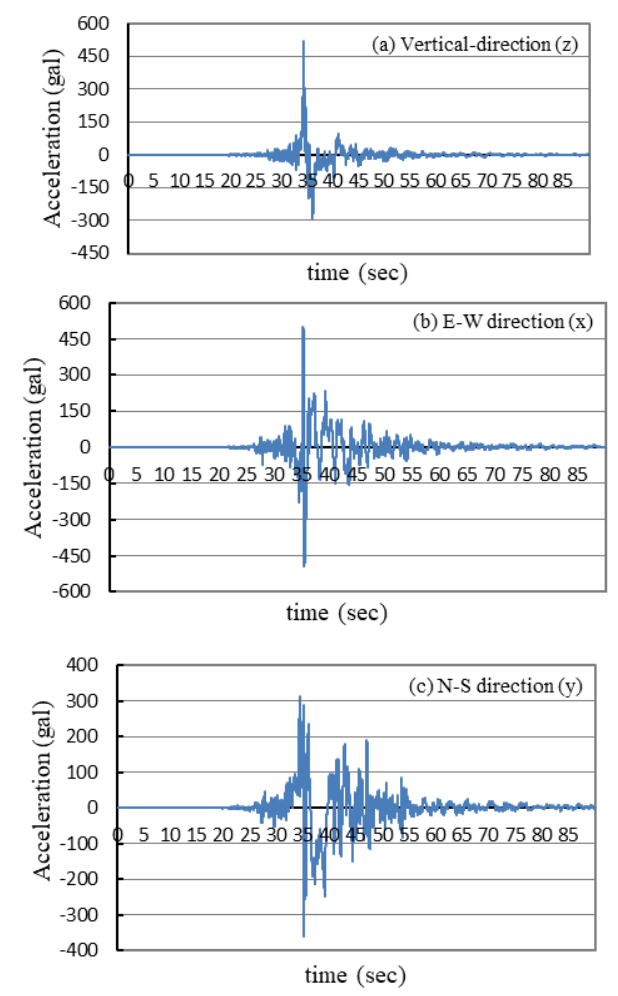

Fig. 2. Time history data of the acceleration recorded at the Shihgang Dam station during the Chi-Chi earthquake in 1999 in Taiwan (a) vertical direction, (b) E-W direction, (c) N-S direction.

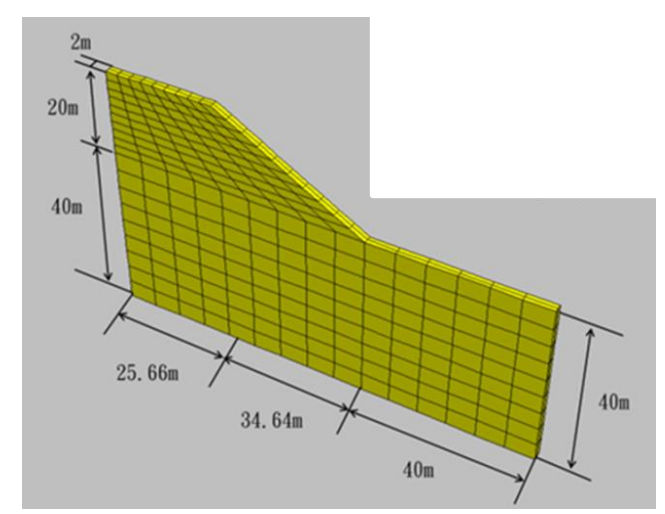

Fig. 3. Finite difference grids and corresponding dimensions for modeling a $30^{\circ}$ slope.

\section{RESUlTS AND DISCUSSION}

\section{A. Seismic Analysis}

The FS of the slope under static conditions was 1.13. The failure surface is the circular failure mode. In general, the slope had an FS larger than 1.0 under the seismic analysis (Fig. 4). The seismic analysis revealed the highest FS for the N-S direction; this was because the maximum acceleration was smaller in the $\mathrm{N}-\mathrm{S}$ direction than in the $\mathrm{E}-\mathrm{W}$ and vertical directions. The FS in the combination of $\mathrm{E}-\mathrm{W}$ and $\mathrm{N}-\mathrm{S}$ directions was close to the results of seismic analysis in the vertical and $\mathrm{E}-\mathrm{W}$ directions separately. The FS of the slope in 
the $\mathrm{N}-\mathrm{S}$ direction was less strongly affected by seismic shaking. However, the slope was in an unstable state with an FS of 0.97 in all three directions during the seismic analysis. Thus, seismic shaking in all directions should be considered during seismic analysis.

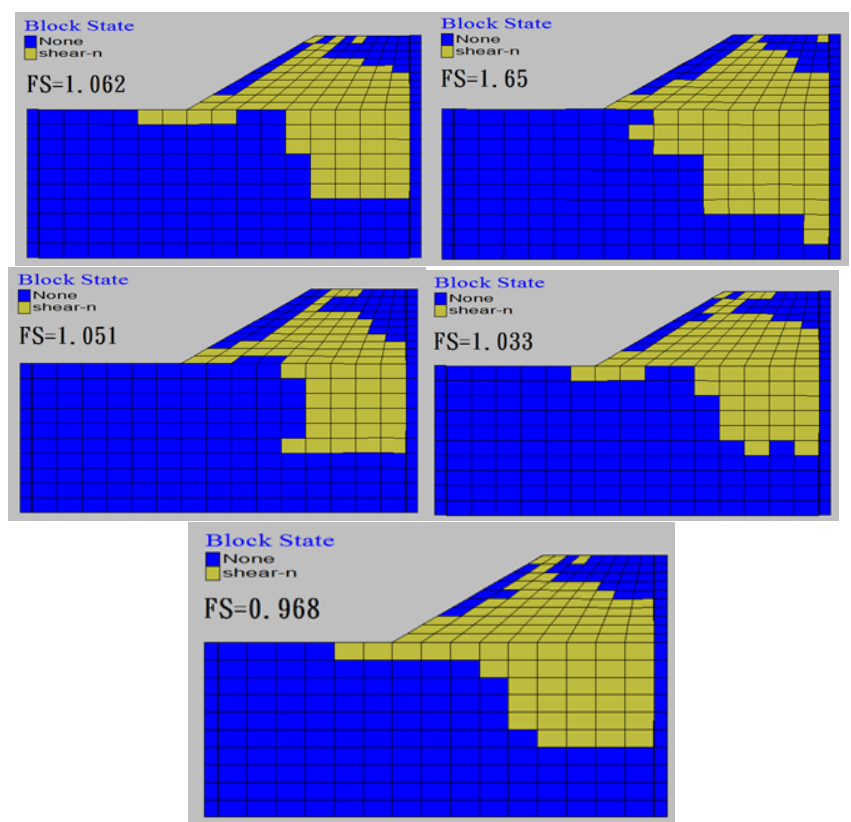

Fig. 4. Results of conducting seismic analysis (a) E-W direction, (b) N-S direction, (c) vertical direction, (d) combination of E-W and N-S directions, (e) three directions

\section{B. Seepage Analysis}

Rainfall causes the water level of the water table to increase due to an increase in the pore water pressure. The water seepage into the ground due to gravity is presented in Fig. 7.

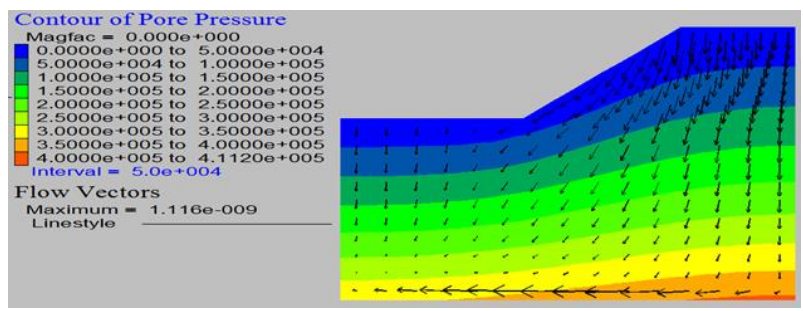

Fig. 7. Distribution of seepage water flow vectors and the increase in water level.

The FS of the slope was reduced from 1.13 (when static conditions were considered) to 1.01 (after rainfall seepage) (Fig. 8). The potential circular failure area was deeper for the rainfall seepage conditions than for the static conditions. This deeper failure area could be due to the reduction in soil shear strength after soil saturation under gravity.

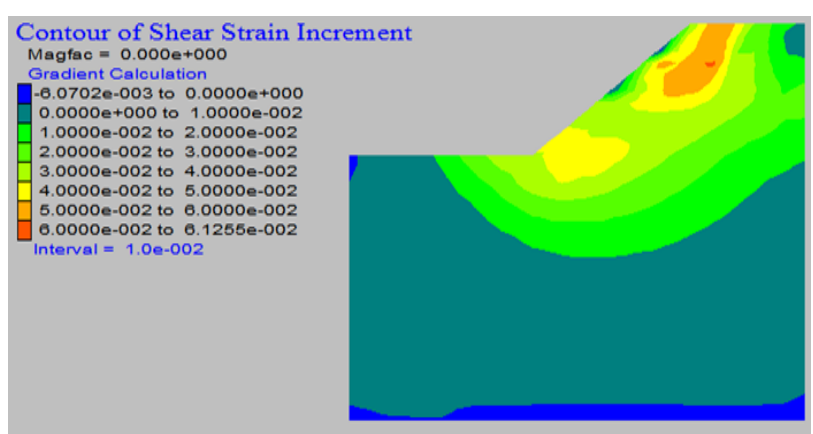

Fig. 8. Shear strain increment contour after rainfall seepage $(\mathrm{FS}=1.01)$.

\section{Seismic Analysis after Rainfall Seepage}

The effect of an earthquake and rainfall seepage on the FS of the slope was investigated by increasing the level of water in the water table after seepage. The soil stress state and water table were not altered for the subsequent seismic analysis. As presented in Fig. 9, the horizontal seismic analyses obtained an FS value of 0.75 and 0.78 , respectively. The FS was 0.79 in the vertical direction when evaluating the slope stability after seismic shaking. The FS of the slope was 0.72 and 0.71 in the two-directional and three-directional seismic analysis (Fig. 10), respectively, which is similar. The figure displays that the effect of seismic shaking in the horizontal direction on the FS of the slope after rainfall seepage was stronger than that in the vertical direction.

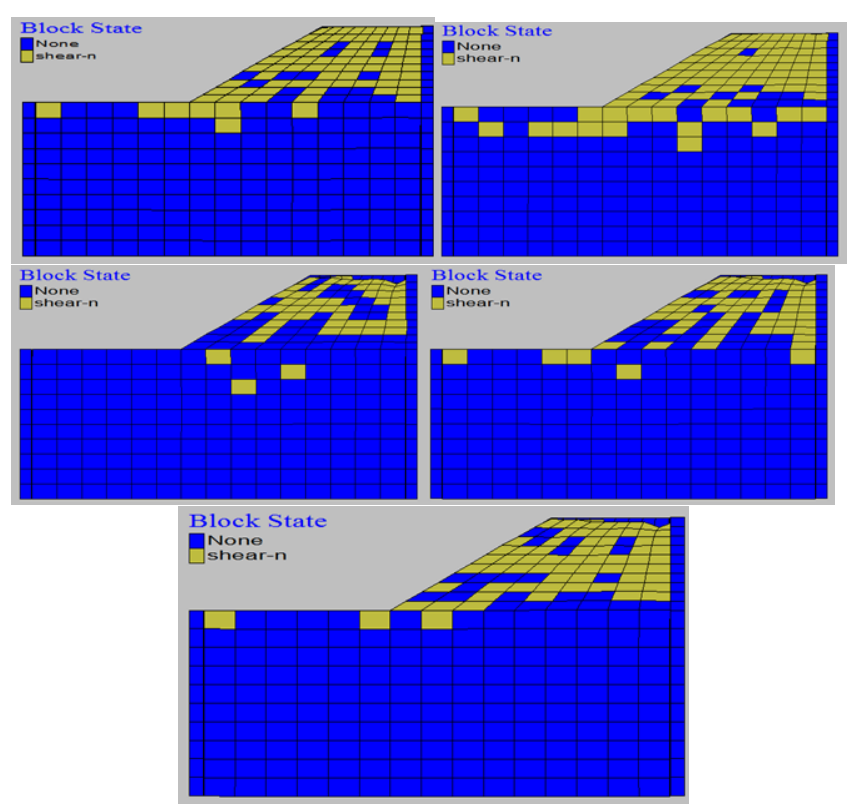

Fig. 9. Plastic deformation of the slope after conducting seismic analysis.

\section{CONCLUSION}

The study employed three cases for analyzing the effects of rainfall seepage, seismic shaking, and seismic shaking after rainfall seepage on a slope's stability. The results reveal that when a slope is subject to seismic shaking in the vertical direction, the FS of the slope is affected less strongly than when the slope is subject to seismic shaking in both the vertical and horizontal directions. Moreover, the FS of the slope is similar for 3D seismic shaking and 2D seismic shaking. Seismic shaking in three directions after seepage alters the failure surface of the slope. The FS of the slope obtained while analyzing the seismic shaking after rainfall seepage was $70 \%$ of the FS of the slope obtained when only analyzing the rainfall seepage condition. This reveals that slope stability can be gauged by considering the combined effect of rainfall seepage and seismic shaking.

\section{REFERENCES}

[1] M. A. H. Zarco, S. G. Catane, H. B. Cabria, R. M. Saturay, and A. S. Mirasol-Robert, "Failure mechanism of a massive landslide: analysis of the 17 February 2006 Guinsaugon rockslide-debris avalanche, Philippines," in Proc. 4th Civil Engineering Conference in the Asian Region, Taipei, Taiwan, June 26-28, 2007.

[2] Z. H. Yang, H. X. Lan, H. J. Liu, L. P. Li, Y. M. Wu, Y. S. Meng, and $\mathrm{L}$. $\mathrm{Xu}$, "Post-earthquake rainfall-triggered slope stability analysis in 
the Lushan area," Journal of Mountain Science, vol. 12, pp. 232-242, 2015.

[3] B. Tiwari, B. Ajmera, and D. Tran, "Influence of post-earthquake rainfall on the stability of clay slopes (IPL-192)," Workshop on World Landslide Forum WLF 2017: Advancing Culture of Living with Landslides, 4th World Landslide Forum. Ljubljana, Slovenia, May 29-June 2, pp. 429-436, 2017.

[4] P. K. Luzon, K. Montalbo, J. Galang, J. M. Sabado, C. M. Escape, R. Felix, and A. M. F. Lagmay, "Hazard mapping related to structurally controlled landslides in Southern Leyte, Philippines," Nat. Hazards Earth Syst. Sci., vol. 16, pp. 875-883, 2016.

[5] R. H. Guthrie, S. G. Evans, S. G. Catane, M. A. H. Zarco, and R. M. Saturay Jr, "The 17 February 2006 rock slide-debris avalanche at Guinsaugon Philippines: A synthesis," Bulletin of Engineering Geology and the Environment, vol. 68, pp. 201-213, 2009.

[6] S. Sassa, H. Takahashi, Y. Morikawa, and D. Takano, "Effect of overflow and seepage coupling on tsunami-induced instability of caisson breakwaters," Coastal Engineering, vol. 117, pp. 157-165, 2006.

[7] O. C. Zienkiewicz, C. Humpheson, and R. W. Lewis, "Associated and non-associated viscoplasticity and plasticity in soil mechanics," Géotechnique, vol. 25, pp. 671-689, 1975.

[8] K. Ugai, "A method of calculation of total factor of safety of slopes by elasto-plastic FEM," Soils and Foundations, vol. 29, pp. 190-195, 1989.

[9] D. V. Griffiths and P. A. Lane, "Slope stability analysis by finite elements," Geotechnique, vol. 49, pp. 387-403, 1999.

[10] F. Cai and K. Ugai, "Response of flexible piles under laterally linear movement of the sliding layer in landslides," Canadian Geotechnical Journal, 40, 46-53, 2003.

[11] M. T. Luan, Y. J. Wu, and T. K. Nuan, “A criterion for evaluating slope stability based on development of plastic zone by strength reduction FEM," Journal of Disaster Prevention and Mitigation Engineering, vol. 23, pp. 1-8, 2008.

[12] S. C. Chi and L. J. Guan, "Slope stability analysis by Lagrangian difference method based on shear strength reduction," Chinese
Journal of Geotechnical Engineering, vol. 26, pp. 42-46, 2004. (in Chinese)

[13] R. L. Hermanns, S. Niedermann, S. Ivy-Ochs, and P. W. Kubik, "Rock avalanching into a landslide-dammed lake causing multiple dam failure in Las Conchas valley (NW Argentina) - evidence from surface exposure dating and stratigraphic analyses," Landslides, vol. 1, pp. 113-122, 2004.

[14] Itasca Consulting Group, Inc., "Fast Language Analysis of continua in 3 dimensions," version 3.0, user's manual, Itasca Consulting Group, Inc., 2005.

[15] Q. J. Yen, "Numerical analysis," Beihang University Press, 2000.

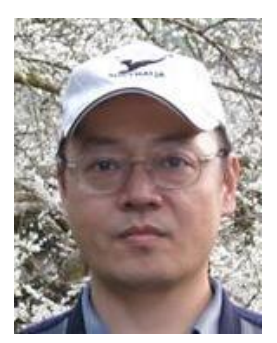

Chien-Yuan Chen was born in Changhua city, Taiwan. He got a Ph.D. in civil \& environmental engineering, University of Southern California, Los Angeles, USA, 2001; a M.Sc. in civil engineering, National Cheng Kung University, Taiwan, 1995.

He was an associate research fellow (2001-2006) at Slopeland Disaster Reduction Division, National Science and Technology Center for Disaster Reduction (NCDR), Sindian District, New Taipei City, Taiwan. He was assistant professor (2006-2009) and associate professor (2009-2013) at Department of Civil and Water Resources Engineering, National Chiayi University. He is currently as Professor (since 2013) and Chairman at Department of Civil and Water Resources Engineering, National Chiayi University, Chiayi City, Taiwan. His research is focused on the following: disaster prevention management and system, Disaster prevention education, Debris flow and landslide hazards prevention and mitigation, geotechnical engineering, GIS application and numerical modeling.

Wei-Cheng Wu was born in Taiwan. M.Sc. in National Chiayi Univ, Taiwan, 2016. He is currently as engineer at a consultant company. His research is focused on the following: geotechnical engineering-pile foundation and slope stability analysis. 